\title{
Inhibitors of Antigen-induced Degranulation of RBL-2H3 Cells Isolated from Amomum tsao-ko
}

\author{
Wonsik Jeong $^{1} \cdot$ Seong Su Hong $^{1}$ (D) - Sun-Mi Park ${ }^{1} \cdot$ Jung A Lee $^{1} \cdot$ Ju-Hyoung Park ${ }^{2}$ \\ Eun-Kyung Ahn ${ }^{1}$. Chun Whan Choi ${ }^{1} \cdot$ Joa Sub Oh${ }^{2}$
}

\section{초과(草果)의 RBL-2H3 세포 항원 유도 탈과립 억제성분}

\author{
정 원식 $^{1} \cdot$ 홍성수 $^{1} \cdot$ 박선미 $^{1}$ - 이정아 ${ }^{1} \cdot$ 박주형 $^{2} \cdot$ 안은경 $^{1}$ - 최춘환 ${ }^{1}$ 오좌섭 ${ }^{2}$
}

Received: 4 November 2020 / Accepted: 28 December 2020 / Published Online: 31 March 2021

(C) The Korean Society for Applied Biological Chemistry 2021

\begin{abstract}
Bioactivity-guided fractionation of EtOH extract of the dried fruits of Amomum tsao-ko led to isolation of three compounds (1-3). Their structures were elucidated by spectroscopic methods (MS, 1D and 2D-NMR) and comparison with literature values, as naringenin-5-O-methyl ether (1), helichrysetin (2), and cardamomin (3). Compound $\mathbf{2}$ was obtained from the genus Amomum for the first time. Among them, compounds $\mathbf{2}$ and $\mathbf{3}$ inhibited on the release of $\beta$-hexosaminidase from RBL-2H3 cells, with 99.1 and $21.3 \%$ at the concentration of $50 \mu \mathrm{M}$, respectively.
\end{abstract}

Keywords Amomum tsao-ko $\cdot \beta$-hexosaminidase $\cdot$ Flavonoid RBL-2H3

W. Jeong and S. S. Hong contributed equally.

Joa Sub Oh $(\bowtie)$

E-mail: jaoh@dankook.ac.kr

${ }^{1}$ Bio-Center, Gyeonggido Business \& Science Accelerator (GBSA), Suwon, Gyeonggi 16229, Republic of Korea

${ }^{2}$ College of Pharmacy, Dankook University, Cheonan, Chungnam 31116, Republic of Korea

This is an Open Access article distributed under the terms of the Creative Commons Attribution Non-Commercial License (http://creativecommons. org/licenses/by-nc/3.0/) which permits unrestricted non-commercial use, distribution, and reproduction in any medium, provided the original work is properly cited.
서 론

초과(草果, Amomum tsao-ko)는 생강과에 속하고 예로부터 향신 료, 조미료, 그리고 중국 전통 의학으로 사용되어 왔으며 [1,2] 따 뜻하고 매운 성질의 초과는 전통적으로 소화불량, 위장병, 거담, 말라리아, 메스꺼움, 구토, 설사 그리고 복통 등에 사용해 왔다[35]. 이 식물에 대한 성분 연구로는 terpenoids, phenolic compounds, flavonoids, carbaldehydes, sterols, diaryheptanoids, benzaldehyde 및 cycloterpenals 등이 보고되어 있으며[6-11], 이들 성분중에서 $\mathrm{He}$ 등[12]은 diarylheptanoids계열 amomutsaokols A-K에서 $\alpha$ glucosidase 억제 활성( $\mathrm{He}$ 등 2020)과, $\mathrm{Kim}$ 등[13]은 pyranoflavanone과 pyranochalcone 계열 화합물로부터 강력한 nitric oxide 생성 억제 활성을 보고하였다. 또한, 초과의 생리활성 연 구로는 항염, 항산화, 항진균 및 항비만 효능 등이 알려져 있다 $[1,11,14-16] . \mathrm{IgE}$ 가 관여하여 일어나는 제 1 형 과민반응은 allergy 또는 아토피 반응으로 불리우며, 아토피 질환, 천식, allergy성 비염 등을 포함하는 가장 흔한 만성 면역계 질환이다 [17]. 비만세포는 대부분의 allergy 질환에 중요한 역할을 하는 세 포로 알려져 있으며, 항원과 항체의 결합을 통하여 활성화되며 세포의 과립 내에 저장되어 있던 히스타민, 염증촉진 사이토카 인과 케모카인, 류코트리엔, 그리고 프로스타글란딘과 같은 allergy 유발물질을 분비한다[18]. 따라서, allergy 유발물질의 탈과립 억 제를 통한 비만세포 활성화 조절은 allergy 반응의 약물 개발에 중요한 자료로 활용될 수 있을 것이다[19]. Allergy 질환의 예방을 위한 기존에 연구된 천연물 소재로는 충울자(Leonurus sibiricus) 추 출물[20], 검정콩 껍질 유래 안토시아닌[21], 곰솔(Pinus thunbergii) 로부터 분리한 neolignane 등[22]이 보고되었다. 본 연구에서는 초과(草果)의 성분 및 효능에 대한 연구를 수행하였으며 에탄올 추출물로부터 분리 정제된 화합물의 RBL-2H3 세포로부터 탈과 립 억제 활성을 확인하였기에 그 결과를 보고하고자 한다. 
재료 및 방법

\section{실험 재료}

실험에 사용한 초과(草果)는 2012년 2월 서울 경동시장에서 구 입하여 교신저자인 오좌섭 교수로부터 형태학적 평가를 통하여 동정 받은 후 사용하였으며, 표본(G47)은 (재)경기도경제과학진 흥원 천연물연구팀 표본실에 보관하고 있다.

\section{시약 및 기기}

비선광도는 JASCO P-2000 polarimeter (Tokyo, Japan)를 사용 하여 측정하였다. Nuclear magnetic resonance (NMR)은 Bruker Ascend III 700 ( $700 \mathrm{MHz}$, cryoprobe) spectrometer (Bruker BioSpin GmbH., Rheinstetten, Germany)를 이용하여 측정하였으며, Electrospray ionization (ESI) mass는 LTQ Orbitrap XL mass spectrometer (Thermo Fisher Scientific Inc., MA, Waltham, USA)를 사용하였다. TLC plate는 Merck 의 Kiesel gel $60 \mathrm{~F}_{254}(0.25 \mathrm{~mm}$, Darmstadt, Germany) 또는 $\mathrm{RP}-18_{254 \mathrm{~S}}(0.25 \mathrm{~mm})$ 를 사용하였다. 컬럼 충진제는 실리카겔 60 (70-230 Mesh, Merck KGaA), 실리카겔 60 (230-400 Mesh, Merck KGaA), ODS-A (12 nm S-75 $\mu \mathrm{m}$, YMC GEL), Sephadex ${ }^{\mathrm{TM}}$ LH-20 (GE Healthcare, IL, Chicago, USA)를 사용하였다. 발 색시약으로는 $10 \%$ vanillin $/ \mathrm{H}_{2} \mathrm{SO}_{4}$ (in $\mathrm{EtOH}$ ) 시약을 사용하였 으며, $\mathrm{UV}$ 의 검색은 254 와 $365 \mathrm{~nm}$ 에서 확인하였다. 추출, 분획 및 컬럼 크로마토그래피에 사용한 모든 용매는 1 급 시약을 사 용하였다. 물은 초순수제조장치 $\left(\mathrm{Cascada}^{\mathrm{TM}} \mathrm{RO}\right.$ water, Pall Corporation, NY, Port Washington, USA)를 이용하여 3차 증 류수를 사용하였다.

\section{추출 및 분리}

건조분말 초과(草果) $5 \mathrm{~kg}$ 에 $80 \%$ 에탄올 $(2 \times 30 \mathrm{~L})$ 를 가하여 24 시간동안 냉침 추출하였다. 그 후 추출물을 여과하여 농축기 (Rotavapor R-250, Büchi Labortechnik GmbH, Flawil, Switzerland) 로 $40{ }^{\circ} \mathrm{C}$ 에서 감압농축 하여 $\mathrm{EtOH}$ 추출물 $219 \mathrm{~g}$ 을 확보하였다. 농축된 시료에 대하여 증류수 $500 \mathrm{~mL}$ 을 가하여 현탁시키고 상 법에 따라 동량의 methylene chloride $\left(\mathrm{CH}_{2} \mathrm{Cl}_{2}\right)$, ethyl acetate (EtOAc) 및 $n-\mathrm{BuOH}$ 순으로 용매 분획한 후 농축시켜 $\mathrm{CH}_{2} \mathrm{Cl}_{2}$ 가용성 분획 $66 \mathrm{~g}, \mathrm{EtOAc}$ 가용성 분획 $18 \mathrm{~g}$, 및 $\mathrm{n}-\mathrm{BuOH}$ 가용 성 분획 $50 \mathrm{~g}$ 을 얻었다. $\mathrm{CH}_{2} \mathrm{Cl}_{2}$ 가용물을 다시 $n$-hexane에 현 탁시키고 $50 \%(32 \mathrm{~g}), 70 \%(8 \mathrm{~g}), 90 \% \mathrm{MeOH}(12 \mathrm{~g})$, 및 $n$ hexane $(10 \mathrm{~g})$ 순으로 각각 분획하였다. 항알러지 효과가 있는 $70 \% \mathrm{MeOH}$ 가용물에 대하여 $\mathrm{CHCl}_{3}-\mathrm{MeOH}$ 혼합용매를 이동상 $(1: 0 \rightarrow 1: 1, \mathrm{v} / \mathrm{v}, 2 \mathrm{~L})$ 으로 하여 silica gel (70-230 Mesh, Merck, Germany)을 이용한 컬럼 크로마토그래피 $(\varnothing 8 \times 30 \mathrm{~cm})$ 를 수행하 여 7개의 소분획(G47-70M-1-7)으로 나누었다. G47-70M-4 소분 획물 $(1.1 \mathrm{~g})$ 에 대하여 $\mathrm{MeOH}$ 와 증류수 혼합용매를 이동상 $(20: 80 \rightarrow 100: 0, \mathrm{v} / \mathrm{v}, 500 \mathrm{~mL})$ 으로 하여 역상 ODS-A $(12 \mathrm{~nm} \mathrm{~S}$ $75 \mu \mathrm{m}$, YMC GEL)을 이용한 VLC (vacuum liquid chromatography, $\varnothing 16 \times 6 \mathrm{~cm})$ 를 수행하여 6 개의 소분획 $(\mathrm{G} 47-70 \mathrm{M}-4-1-6)$ 을 얻었다. G47-70M-4-4 (150 mg)에 대하여 $\mathrm{CHCl}_{3}-\mathrm{MeOH}$ 혼합용매를 이 동상 $(20: 1 \rightarrow 6: 1, \mathrm{v} / \mathrm{v}, 200 \mathrm{~mL})$ 으로 하여 silica gel $(230-400$ Mesh, Merck, Germany)을 이용한 컬럼 크로마토그래피(ø1.5× $25 \mathrm{~cm})$ 를 수행하여 화합물 1 (3.2 mg)을 분리하였다. 소분획
G47-70M-4-3 (600 mg)에 대하여 $\mathrm{CHCl}_{3}-\mathrm{MeOH}(1: 1, \mathrm{v} / \mathrm{v}, 2 \mathrm{~L})$ 혼합용매를 이동상으로 하여 Sephadex $^{\mathrm{TM}} \mathrm{LH}-20$ 을 이용한 컬럼 크로마토그래피 $(\varnothing 4 \times 150 \mathrm{~cm})$ 를 수행하여 화합물 $2(5.7 \mathrm{mg})$ 와 3 $(7.3 \mathrm{mg})$ 을 각각 분리 정제하였다.

화합물 1 (naringenin-5-O-methyl ether): White amorphous powder;

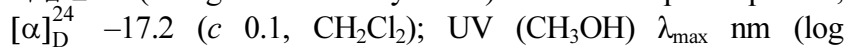
$\varepsilon): 226$ (4.12), 283 (3.93), 323sh (3.25); ${ }^{1} \mathrm{H}$ NMR (DMSO$\left.d_{6}, 700 \mathrm{MHz}\right): \delta 7.29\left(2 \mathrm{H}, \mathrm{d}, J=8.5 \mathrm{~Hz}, \mathrm{H}-2^{\prime}, 6^{\prime}\right), 6.77$ $\left(2 \mathrm{H}, \mathrm{d}, J=8.8 \mathrm{~Hz}, \mathrm{H}-3^{\prime}, 5^{\prime}\right), 6.05(1 \mathrm{H}, \mathrm{d}, J=2.1 \mathrm{~Hz}, \mathrm{H}-6)$, $5.95(1 \mathrm{H}, \mathrm{d}, J=2.1 \mathrm{~Hz}, \mathrm{H}-8), 5.33(1 \mathrm{H}, \mathrm{dd}, J=12.6,2.8$ $\mathrm{Hz}, \mathrm{H}-2), 3.73\left(3 \mathrm{H}, \mathrm{s}, \mathrm{OCH}_{3}\right), 2.99(1 \mathrm{H}, \mathrm{dd}, J=16.8,12.6$ $\left.\mathrm{Hz}, \mathrm{H}_{\mathrm{a}}-3\right), 2.48\left(1 \mathrm{H}, \mathrm{dd}, J=16.8,2.8 \mathrm{~Hz}, \mathrm{H}_{\mathrm{b}}-3\right) ;{ }^{13} \mathrm{C}$ NMR (DMSO- $d_{6}, 175$ MHz): $\delta 188.2$ (C-4), 164.8 (C-7), 164.7 (C-9), 162.7 (C-5), 158.0 (C-4'), 129.8 (C-1'), 128.6 (C-2', 6'), 115.6 (C-3', 5'), 104.9 (C-10), 96.1 (C-8), 93.7 (C-6), $78.5(\mathrm{C}-2), 56.1\left(\mathrm{OCH}_{3}\right), 45.2$ (C-3); ESIMS (negative ion mode) $\mathrm{m} / z 285[\mathrm{M}-\mathrm{H}]^{-}$.

화합물 2 (helichrysetin): Yellow amorphous powder; UV $\left(\mathrm{CH}_{3} \mathrm{OH}\right) \lambda_{\max } \mathrm{nm}(\log \varepsilon): 364$ (4.13); ${ }^{1} \mathrm{H}$ NMR (DMSO- $d_{6}$, $700 \mathrm{MHz}): \delta 13.94\left(1 \mathrm{H}, \mathrm{s}, 2^{\prime}-\mathrm{OH}\right), 10.61\left(1 \mathrm{H}, \mathrm{s}, 4{ }^{\prime}-\mathrm{OH}\right)$, $10.09(1 \mathrm{H}, \mathrm{s}, 4-\mathrm{OH}), 7.67$ (1H, d, $J=15.4 \mathrm{~Hz}, \mathrm{H}-\alpha), 7.63$ $(1 \mathrm{H}, \mathrm{d}, J=15.4 \mathrm{~Hz}, \mathrm{H}-\beta), 7.57(2 \mathrm{H}, \mathrm{dd}, J=8.4 \mathrm{~Hz}, \mathrm{H}-2$, 6), $6.84(2 \mathrm{H}, \mathrm{dd}, J=8.4 \mathrm{~Hz}, \mathrm{H}-3,5), 6.01(1 \mathrm{H}, \mathrm{d}, J=2.1$ $\left.\mathrm{Hz}, \mathrm{H}-5^{\prime}\right), \quad 5.91 \quad\left(1 \mathrm{H}, \mathrm{d}, J=2.1 \mathrm{~Hz}, \mathrm{H}-3^{\prime}\right), 3.88 \quad(3 \mathrm{H}, \mathrm{s}$, $\left.\mathrm{OCH}_{3}\right) ;{ }^{13} \mathrm{C}$ NMR (DMSO- $\left.d_{6}, 175 \mathrm{MHz}\right): \delta 191.7(\mathrm{C}=\mathrm{O})$, 166.3 (C-2'), 164.6 (C-4'), 162.5 (C-6'), 159.9 (C-4), 142.7 (C- $\beta), 130.4$ (C-2, 6), 125.9 (C-1), 123.7 (C- $\alpha), 115.9$ (C-3, 5), $\quad 105.0$ (C-1'), $95.8 \quad\left(\mathrm{C}-3^{\prime}\right), \quad 91.6 \quad\left(\mathrm{C}-5^{\prime}\right), \quad 55.9 \quad\left(\mathrm{OCH}_{3}\right)$; ESIMS (negative ion mode) $\mathrm{m} / \mathrm{z} 285[\mathrm{M}-\mathrm{H}]^{-}$.

화합물 3 (cardamomin): Yellow amorphous powder; UV $\left(\mathrm{CH}_{3} \mathrm{OH}\right) \lambda_{\max } \mathrm{nm}(\log \varepsilon)$ : 343 (4.25); ${ }^{1} \mathrm{H}$ NMR (DMSO- $d_{6}$, $700 \mathrm{MHz}): \delta 13.72\left(1 \mathrm{H}, \mathrm{s}, 2^{\prime}-\mathrm{OH}\right), 10.61$ (1H, s, 4'-OH), $7.83(1 \mathrm{H}, \mathrm{d}, J=16.1 \mathrm{~Hz}, \mathrm{H}-\alpha), 7.72(2 \mathrm{H}, \mathrm{dd}, J=7.7,1.4$ $\mathrm{Hz}, \mathrm{H}-2,6), 7.66$ (1H, d, $J=16.1 \mathrm{~Hz}, \mathrm{H}-\beta), 7.46(3 \mathrm{H}$, overlapped, H-3, 4, 5), $6.03\left(1 \mathrm{H}, \mathrm{d}, J=2.1 \mathrm{~Hz}, \mathrm{H}-5^{\prime}\right), 5.93$ $\left(1 \mathrm{H}, \mathrm{d}, J=2.1 \mathrm{~Hz}, \mathrm{H}-3^{\prime}\right), 3.89\left(3 \mathrm{H}, \mathrm{s}, \mathrm{OCH}_{3}\right) ;{ }^{13} \mathrm{C} \mathrm{NMR}$ $\left(\mathrm{DMSO}-d_{6}, 175 \mathrm{MHz}\right): \delta 191.7(\mathrm{C}=\mathrm{O}), 166.2\left(\mathrm{C}-2^{\prime}\right), 165.0$ (C-4'), 162.7 (C-6'), 141.7 (C- $\beta), 134.9$ (C-1), 130.3 (C-4), 129.0 (C-3, 5), 128.3 (C-2, 6), 127.5 (C- $\alpha), 105.1$ (C-1'), $95.8\left(\mathrm{C}-3^{\prime}\right), 91.7\left(\mathrm{C}-5^{\prime}\right), 56.0\left(\mathrm{OCH}_{3}\right)$; ESIMS (negative ion mode) $\mathrm{m} / z 269[\mathrm{M}-\mathrm{H}]^{-}$.

\section{RBL-2H3 세포배양 및 탈과립화 측정}

Rat basophilic leukemia 셀 라인인 RBL-2H3 세포주를 $15 \%$ FBS, $100 \mathrm{unit} / \mathrm{mL}$ 의 페니실린과 스트렙토마이신을 포함하는 $\mathrm{MEM}$ 배지와 $37^{\circ} \mathrm{C}, 5 \% \quad \mathrm{CO}_{2}$ 조건에서 24 well plate에 $2 \times 10^{5}$ cells/well로 분주한 후 24 시간 배양하였다. 상등액을 제거 후 $25 \mathrm{ng} / \mathrm{mL}$ anti-DNP IgE가 포함된 MEM 배지를 넣고 4시 간 배양 후 PIPES buffer $500 \mu \mathrm{L}$ 로 두 번 세척하고 $4 \mathrm{mM}$ $\mathrm{MgCl}_{2}, 5.6 \mathrm{mM}$ glucose, $0.1 \% \mathrm{BSA}$ 를 포함시킨 PIPES buffer 를 $180 \mu \mathrm{L}$ 넣고 10 분 동안 배양하였다. 전 배양 후 실시예의 
<smiles>COc1cc(O)cc2c1C(=O)C[C@H](c1ccc(O)cc1)O2</smiles>

1<smiles>[R]c1ccc(/C=C/C(=O)c2c(O)cc(O)cc2OC)cc1</smiles>

$2 \mathrm{R}=\mathrm{OH}$

Fig. 1 Chemical structures of compounds $\mathbf{1 - 3}$ identified from the fruits of $A$. tsao-ko

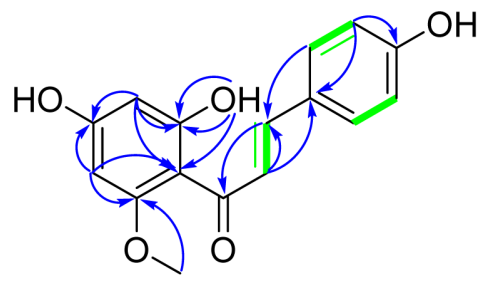

2

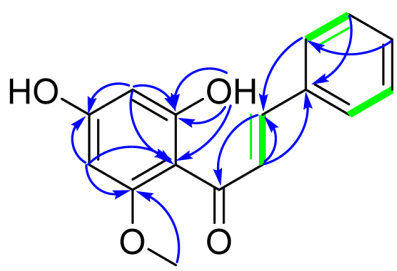

3
${ }^{1} \mathrm{H}-{ }^{-1} \mathrm{H} \cos Y$
$\mathrm{HMBC}, \mathrm{H}$ to $\mathrm{C}$

Fig. 2 Selected ${ }^{1} \mathrm{H}-{ }^{1} \mathrm{H}$ COSY and $\mathrm{HMBC}$ correlation of compounds $\mathbf{2}$ and $\mathbf{3}$

시료를 $25,50,100 \mu \mathrm{g} / \mathrm{mL}$ 의 농도로 20 분간 처리 후 $50 \mathrm{ng} / \mathrm{mL}$ DNP-BSA 20분간 반응시켰다. Ice에서 10 분 방치하여 반응을 종결시킨 후 상등액을 $30 \mu \mathrm{L}$ 씩 96 웰 플레이트에 넣고, $1 \mathrm{mM}$ $\mathrm{P}$-니트로페닐-아세틸- $\beta$-D-글루코사미니드를 $30 \mu \mathrm{L}$ 넣은 후 37 ${ }^{\circ} \mathrm{C}$ 에서 1 시간 반응시켰다. stop solution $\left(0.1 \mathrm{M} \mathrm{NaHCO}_{3}, 0.1 \mathrm{M}\right.$ $\mathrm{Na}_{2} \mathrm{CO}_{3}$ )을 넣고 반응을 종결시킨 후 $405 \mathrm{~nm}$ 파장대에서 ELISA 리더로 흡광도를 측정하였다.

\section{결과 및 고찰}

초과(草果)로부터 얻은 $80 \%$ 에탄올 추출물에 대하여 통상적인 방법으로 분획하여 $\mathrm{CH}_{2} \mathrm{Cl}_{2}, \mathrm{EtOAc}$ 및 $n-\mathrm{BuOH}$ 분획물을 제조 하였다. 이 중 $\mathrm{CH}_{2} \mathrm{Cl}_{2}$, 분획물에 대하여 $n$-hexane과 50,70 , $90 \% \mathrm{MeOH}$ 로 분획 하였고, $70 \% \mathrm{MeOH}$ 가용 분획물에 대하 여 실리카겔, ODS, Sephadex LH-20 컬럼 크로마토그래피를 이 용하여 3 종의 화합물을 분리, 정제하였다. 분리한 화합물은 $1 \mathrm{D}-, 2 \mathrm{D}-\mathrm{NMR}$ 및 $\mathrm{MS}$ 등의 기기분석 및 문헌과의 비교를 통 하여 그 구조를 규명하였다(Fig. 1).

화합물 1은 흰색 무정형 분말로서 $226,283,323 \mathrm{sh} \mathrm{nm}$ 의 UV 흡수극대치와 NMR 및 ESI-MS spectral data로부터 분자량 $286\left(\mathrm{~m} / \mathrm{z} 285 \quad[\mathrm{M}-\mathrm{H}]^{-}\right)$의 flavanone 화합물로 추정하였다 [23,24]. ${ }^{1} \mathrm{H}-\mathrm{NMR}$ 스펙트럼의 $\delta_{\mathrm{H}} 7.29(2 \mathrm{H}, \mathrm{d}, J=8.5 \mathrm{~Hz})$ 및 $6.77(2 \mathrm{H}, \mathrm{d}, J=8.5 \mathrm{~Hz})$ 에서 flavanone B-ring의 $\rho$-disubstituted benzene ring에 의한 signal이 관찰되었고, $\delta_{\mathrm{H}} 6.05(1 \mathrm{H})$ 와 $5.95(1 \mathrm{H})$ 에서 H-6 및 H-8 proton이 커플링 상수 $J=2.1 \mathrm{~Hz}$ 의 doublet으로 각각 나타났다. $\delta_{\mathrm{H}} 5.33(1 \mathrm{H}, \mathrm{dd}, J=12.6,2.8$ $\mathrm{Hz}), 2.99$ (dd, $J=16.8,12.6 \mathrm{~Hz}$ ), 및 2.48 (dd, $J=16.8,2.8$ $\mathrm{Hz}$ )에서 flavanone 유도체임을 알 수 있는 C-ring의 $\mathrm{H}-2, \mathrm{H}_{\mathrm{a}}-3$, $\mathrm{H}_{\mathrm{b}}-3$ proton signal과, $\delta_{\mathrm{H}} 3.73(3 \mathrm{H}, \mathrm{s})$ 에서 한 개의 methoxy
그룹을 각각 확인하였다. ${ }^{13} \mathrm{C}-\mathrm{NMR}$ 와 $\mathrm{DEPT}$ 스펙트럼에서 $\rho-$ disubstituted benzene ring의 중복된 탄소 $\left(\delta_{\mathrm{C}} \quad 128.6\right.$ 과 115.6)와 $\delta_{\mathrm{C}} 56.1$ 의 methoxy 그룹을 포함하여 총 16 개의 신호를 확인하 였으며, $\mathrm{HMBC}$ 스펙트럼으로부터 methoxy 그룹의 수소 $\left(\delta_{\mathrm{H}}\right.$ 3.87)가 C-5 ( $\delta_{\mathrm{C}}$ 163.2)와 correlation 하는 것을 통해 methoxy 그룹은 C-5 위치에 결합하고 있음을 결정하였다. 또한, C-2 위 치의 stereochemistry는 H-2와 H-3 proton의 커플링 상수와 비 선광도 측정치 $\left([\alpha]_{\mathrm{D}}^{24}-17.2\right)$ 를 문헌 $\left([\alpha]_{\mathrm{D}}^{25}-14.0\right)$ 과 비교하여 $S$-form임을 알 수 있었으며, 이상의 결과를 문헌과의 비교로 화 합물 1은 naringenin-5-O-methyl ether로 구조를 규명하였다[25]. 화합물 2는 황색 무정형 분말로 분리, 정제되었으며, negative 이온 모드의 ESI-MS에서 $285[\mathrm{M}-\mathrm{H}]^{-}$의 이온 피크를 관찰하여 분자량은 286으로 확인하였다. UV spectrum에서 흡수극대파장 $\left(\lambda_{\max }\right)$ 이 $364 \mathrm{~nm}$ 에서 나타나 chalcone 계열에 속하는 것으로 예 상되었다[26,27]. ${ }^{1} \mathrm{H}-\mathrm{NMR}$ 스펙트럼에서 chalcone 골격의 $\mathrm{C}-\alpha$ 와 C- $\beta$ 위치에 해당하는 한 쌍의 trans olefinic 수소를 $\delta_{\mathrm{H}}$ $7.67(1 \mathrm{H}, \mathrm{d}, J=15.4 \mathrm{~Hz}, \mathrm{H}-\alpha)$ 와 $7.63(1 \mathrm{H}, \mathrm{d}, J=15.4 \mathrm{~Hz}$, $\mathrm{H}-\beta)$ 에서 확인하였고, $\rho$-disubstituted benzene ring의 수소 $\delta_{\mathrm{H}}$ $7.57(2 \mathrm{H}, \mathrm{d}, J=9.1 \mathrm{~Hz}, \mathrm{H}-2,6)$ 과 $6.85(2 \mathrm{H}, \mathrm{d}, J=9.1 \mathrm{~Hz}$, $\mathrm{H}-3,5)$ 를 관찰하였다. 또한, meta-coupling을 하고 있는 aromatic doublet 수소를 $\delta_{\mathrm{H}} 6.03\left(1 \mathrm{H}, \mathrm{d}, J=2.1 \mathrm{~Hz}, \mathrm{H}-5^{\prime}\right)$ 과 $5.93\left(1 \mathrm{H}, \mathrm{d}, J=2.1 \mathrm{~Hz}, \mathrm{H}-3^{\prime}\right)$ 에서, 한 개의 hydrogen-bonded hydroxy group [ $\left.\delta_{\mathrm{H}} 13.94(\mathrm{~s})\right]$ 과 methoxy 그룹 [ $\left.\delta_{\mathrm{H}} 3.87(3 \mathrm{H}, \mathrm{s})\right]$ 을 확인하였다. ${ }^{13} \mathrm{C}-\mathrm{NMR}$ 와 DEPT 스펙트럼에서 $\rho$-disubstituted benzene ring의 중복된 탄소를 포함하여 총 16 개의 신호를 확 인하였으며, 그 중 1 개분에 해당하는 탄소를 포함하여 chalcone 골격에 methoxy 그룹 1 개가 결합하고 있는 구조로 유추하였다. $\mathrm{HMBC}$ 스펙트럼에서 methoxy 그룹이 C-6'에 correlation $\left(\delta_{\mathrm{H}}\right.$ $3.87 / \delta_{\mathrm{C}} 163.2$ ) 하는 것을 통해 C-6'번 위치에 결합한 methoxy 그룹을 확인하였으며(Fig. 2), 이를 참고문헌과 비교하여 화합물 

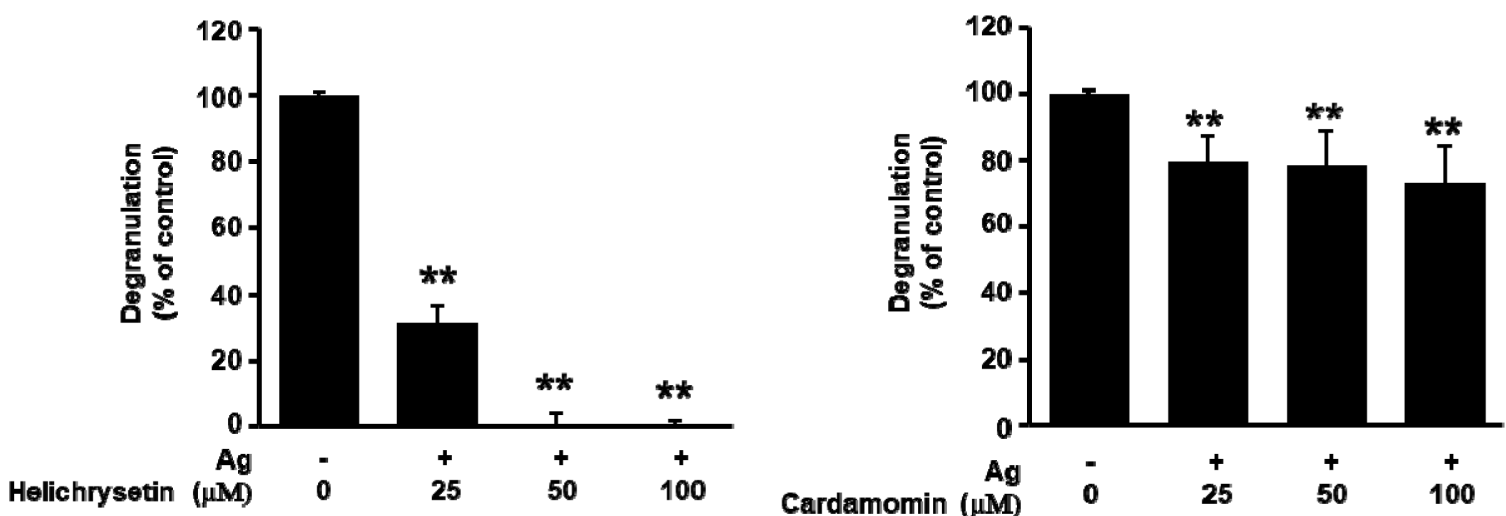

Fig. 3 Effect of helichrysetin (2) and cardamomin (3) on degranulation in RBL-2H3 cells. Cells were grown on 24 well plates $\left(3 \times 10^{5}\right.$ cells/well) and pretreated with compounds $(25,50,100 \mu \mathrm{M})$ for $20 \mathrm{~min}$, followed by antigen stimulation for $30 \mathrm{~min}$. Degranulation was determined by measuring the activity of $\beta$-hexosaminidase as described in Materials and Method. Data are expressed as mean $\pm \mathrm{SD}, * * p<0.01$, compared with antigen-treated cells)

2를 helichrysetin (2',4,4'-trihydroxy-6'-methoxy chalcone)으로 규명하였다[28]. 이는 Amomum속 식물로부터 처음 분리, 보고 되는 화합물이다.

화합물 3은 황색 무정형 분말로 분리되었으며, negative 이온 모드의 ESI-MS에서 $269[\mathrm{M}-\mathrm{H}]^{-}$의 이온 피크를 관찰하여 분자 량은 270으로 확인하였다. UV spectrum에서 흡수극대파장 $\left(\lambda_{\max }\right)$ 이 $343 \mathrm{~nm}$ 에서 나타나 화합물 $\mathbf{3}$ 역시 chalcone 계열에 속 하는 것으로 예상되었다[26,27]. 화합물 3 의 ${ }^{1} \mathrm{H}$ 및 ${ }^{13} \mathrm{C}-\mathrm{NMR}$ 스 펙트럼은 화합물 $\mathbf{2}$ 와 유사하였다. 그러나 화합물 $\mathbf{2}$ 와 달리 mono-substituted benzene ring에 기인하는 수소 $\delta_{\mathrm{H}} 7.72(2 \mathrm{H}$, $\mathrm{dd}, J=7.7,1.4 \mathrm{~Hz}, \mathrm{H}-2,6)$ 와 7.45 (3H, overlapped, H-3, 4, $5)$ 의 관찰과 $\mathrm{ESI}-\mathrm{MS}$ 에서도 $\mathrm{amu} 16$ 의 차이로 화합물 2 의 $\mathrm{B}$ 환 에서 hydroxy 그룹이 결여된 화합물로 추정하였다. $\mathrm{HMBC}$ 스 펙트럼에서 methoxy 그룹의 signal이 C-6'에 correlation $\left(\delta_{\mathrm{H}}\right.$ $3.88 / \delta_{\mathrm{C}} 163.2$ )하는 것을 확인하였고(Fig. 2), 참고문헌[29]과 비 교하여 화합물 3은 cardamomin (2',4'-dihydroxy-6'-methoxy chalcone)으로 동정하였으며 이 식물에서 처음 분리, 보고되는 화합물이다. 초과 추출물에서 분리된 화합물 3종을 이용하여 항 알러지 효능을 확인하기 위해 RBL-2H3 세포로부터 $\beta$ hexosaminidase assay를 수행한 결과 naringenin-5-O-methyl ether (1)은 탈과립화 억제 효과가 없었고 helichrysetin (2)와 cardamomin (3) 처리군에서는 $\beta$-hexosaminidase 억제 효과가 있는 것으로 나타났다(Fig. 3). Table S1에서 보는 바와 같이 helichrysetin (2)는 $100 \mathrm{mM}$ 에서 $99.7 \%$ 이고 cardamomin (3)은 $29.7 \%$ 의 탈과립 억제 효과를 보였다. 이들 화합물 3종은 flavonoid 계열의 화합물로 그 중에서도 화합물 1은 flavanone 골격을 함유하며, 화합물 2 와 3 은 chalcone 골격으로 차이를 보 이며 탈과립화 억제 효과는 chalcone 골격 화합물이 활성을 나 타내었으나, 구조-효능 상관 관계를 규명하기에는 더 많은 화합 물이 필요하다고 사료된다.

\section{초 록}

전통생약으로서 다양한 효능과 향신료, 조미료로서 사용되어온
초과(草果)의 항알레르기 성분연구를 위해 $80 \%$ 에탄올 추출물 중 $\mathrm{CH}_{2} \mathrm{Cl}_{2}$, 분획으로부터 3 종의 flavonoid를 단리하였으며, 이 들의 물리화학적 성상과 분광분석 데이터로부터 구조를 확인한 결과 naringenin-5-O-methyl ether (1), helichrysetin (2) 및 cardamomin (3)로 각각 동정하였다. 이들 화합물 중 화합물 2 는 Amomum 속으로부터 처음 규명되었고, 화합물 3은 이 식물에서 처음 보 고되는 화합물이다. 또한 화합물 2와 3은 RBL-2H3 세포로부터 $\beta$-hexosaminidase assay를 수행한 결과 탈과립 억제효과를 나타 내었다. 따라서 초과의 chalcone 성분은 탈과립 억제효능을 통 하여 알러지 질환에 유용할 것으로 사료된다.

Keywords 초과 · Amomum tsao-ko $\cdot \beta$-hexosaminidase $\cdot$ Flavonoid RBL-2H3

감사의 글 본 논문은 농촌진흥청 연구사업(세부과제번호: PJ01323301)의 지원에 의하여 수행되었으며, 이에 감사드립니다.

\section{References}

1. Moon SS, Lee JY, Cho SC (2004) Isotsaokoin, an antifungal agent from Amomum tsao-ko. J Nat Prod 67: 889-891

2. Yang Y, Yan RW, Cai XQ, Zheng ZL, Zou GL (2008) Chemical composition and antimicrobial activity of the essential oil of Amomum tsao-ko. J Sci Food Agric 88(12): 2111-2116

3. Lim, TK (2013) Edible medicinal and non-medicinal plants. Springer 5: 813-816

4. Yu L, Shirai N, Suzuki H, Sugane N, Hosono T, Nakajima Y, Kajiwara M, Takatori K (2010) The effect of methanol extracts of tsao-ko (Amomum tsao-ko Crevost et Lemaire) on digestive enzyme and antioxidant activity in vitro, and plasma lipids and glucose and liver lipids in mice. J Nutr Sci Vitaminol 56: 171-176

5. Zhao ZZ, Xiao PG (2010) Encyclopedia of medicinal plants. World Publishing Corporation, Hong kong 4: 36-38

6. Hong SS, Lee JH, Choi YH, Jeong W, Ahn EK, Lym SH, Oh JS (2015) Amotsaokonal A-C, benzaldehyde and cycloterpenal from Amomum tsao-ko. Tetrahedron Lett 56: 6681-6684

7. Lee JY, Kim SH, Sung SH, Kim YC (2008) Inhibitory constituents of lipopolysaccharide-induced nitric oxide production in BV2 microglia 
isolated from Amomum tsao-ko. Planta Med 74(8): 867-869

8. Lee JY (2003) Bioactive compounds from medicinal plant, Amomum tsao-ko: Isolation and chemical structures. Dissertation, Kong Ju University

9. Teresita SM, Hiroe K, Masashi H, Nobuji N (2000) Constituents of Amomum tsao-ko and their radical scavenging and antioxidant activities. JAOCS 77(6): 667-673

10. Wang W, Yang CR, Zhang YJ (2005) Phenolic constituents from the fruits of Amomum tsao-ko (Zingiberaceae). Acta Bot Yunnan 31(3): 284-288

11. Yang Y, Yue Y, Runwei Y, Guolin Z (2010) Cytotoxic, apoptotic and antioxidant activity of the essential oil of Amomum tsao-ko. Bioresour Technol 101: 4205-4211

12. He XF, Wang HM, Geng CA, Hu J, Zhang XM, Guo YQ, Chen JJ (2020) Amomutsaokols A-K, diarylheptanoids from Amomum tsao-ko and their $\alpha$ glucosidase inhibitory activity. Phytochemistry 177: 112418/ $1-112418 / 10$

13. Kim JG, Jang H, Le TPL, Hong HR, Lee MK, Hing JT, Lee D, Hwang BY (2019) Pyranoflavanones and pyranochalcones from the fruits of Amomum tsao-ko. J Nat Prod 82: 1886-1892

14. Kim MS, Ahn EK, Hong SS, Oh JS (2016) 2,8-Decadiene-1,10-diol inhibits lipopolysaccharide-induced inflammatory responses through inactivation of Mitogen-activated protein kinase and Nuclear Factor- $\mathrm{kB}$ signaling pathway. Inflammation 39(2): 583-591

15. Lee JA, Park YJ, Jeong W, Hong SS (2017) Anti-obesity effect of Amomum taso-ko ethanol extract in 3T3-L1 adipocytes. J Appl Biol Chem 60(1): 23-28

16. Li B, Choi HJ, Lee DS, Oh H, Kim YC, Moon JY, Park WH, Park SD, Kim JE (2014) Amomum tsao-ko suppresses lipopolysaccharide-induced inflammatory responses in RAW264.7 macrophages via Nrf2-dependent heme oxygenase-1 expression. Am J Chin Med 42(5): 1229-1244

17. Kawamoto $\mathrm{Y}$, Kondo H, Hasegawa M, Kurimoto C, Ishii Y, Kato C, Botei T, Shinya M, Murate T, Ueno Y, Kawabe M, Goto Y, Yamamoto R, Iida M, Yajima I, Ohgami N, Kato M, Takeda K (2019) Inhibition of mast cell degranulation by melanin. Biochem Pharmacol 163: 178-193

18. Nugrahini AD, Ishida M, Nakagawa T, Nishi K, Sugahara T (2019) Anti-degranulation activity of caffeine: In vitro and in vivo study. J Funct Foods 60: 103422/1-103422/8

19. Hu J, Chen Y, Zhu J, Gao M, Li J, Song Z, Xu H, Wang Z (2020) Anti- degranulation response of herbal formula in RBL-2H3 cells. Micron 130: $102819 / 1-102819 / 6$

20. Jung Y, Jeon Y, Kim HJ, Kang KS, Kim YK, Kim SN (2014) Antiallergic and anti-inflammatory effect of Leonurus sibiricus seed ethyl acetate fractions. Yakhak Hoeji 58(5): 294-299

21. Chung MJ, Ha TJ, Choi HN, Lee JS, Park YI (2011) Inhibitory effects of anthocyanins isolated from black soybean (Glycine max L.) seed coat on degranulation and cytokine generation in RBL-2H3 cells. J Korean Soc Food Sci Nutr 40(12): 1662-1667

22. Hong SS, Jeong W, Kim JK, Kwon JG, Lee JY, Ahn EK, Oh J, Seo DW, Oh JS (2014) Neolignan inhibitors of antigen-induced degranulation in RBL-2H3 cells from the needles of Pinus thunbergii. Fitoterapia 99: 347-351

23. Li X, Zhu LJ, Chen JP, Shi CY, Niu LT, Zhang X, Yao XS (2019) CMethylated flavanones from the rhizomes of Matteuccia intermedia and their $\alpha$-glucosidase inhibitory activity. Fitoterapia 136: 104147/1$104147 / 10$

24. Passreiter CM, Suckow-Schnitker AK, Kulawik A, Addae-Kyereme J, Wright CW, Wätjen XW (2015) Prenylated flavanone derivatives isolated from Erythrina addisoniae are potent inducers of apoptotic cell death. Phytochemistry 117: 237-244

25. Kim JG, Le TPL, Hong HR, Han JS, Ko JH, Lee SH, Lee MK, Hwang BY (2019) Nitric oxide inhibitory constituents from the fruits of Amomum tsao-ko. Nat Prod Sci 25(1): 76-80

26. Yoshimura M, Sano A, Kamei, JI, Obata A (2009) Identification and quantification of metabolites of orally administered naringenin chalcone in rats. J Agric Food Chem 57(14): 6432-6437

27. Iwase Y, Takahashi M, Takemura Y, Ju-Ichi M, Ito C, Furukawa H, Yano $M$ (2001) Isolation and identification of two new flavanones and a chalcone from Citrus kinokuni. Chem Pharm Bull 49(10): 1356-1358

28. Aponte JC, Castillo D, Estevez Y, Gonzalez G, Arevalo J, Hammond GB, Sauvain M (2010) In vitro and in vivo anti-Leishmania activity of polysubstituted synthetic chalcones. Bioorg Med Chem Lett 20: 100-103

29. Potipiranun T, Adisakwattana S, Worawalai W, Ramadhan R, Phuwapraisirisan P (2018) Identification of pinocembrin as an antiglycation agent and $\alpha$-glucosidase inhibitor from fingerroot (Boesenbergia rotunda): the tentative structure-activity relationship towards mg-trapping activity. Molecules 23(12): 3365/1-3365/13 